\title{
KULEUYEN
}

DEPARTMENT OF ECONOMICS

\section{The cost of non-TTIP: a global value chain approach}

Hylke VANDENBUSSCHE, William CONNELL and Wouter SIMONS

FACULTY OF ECONOMICS AND BUSINESS

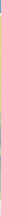

DISCUSSION PAPER SERIES DPS18.02

FEBRUARY 2018 


\title{
The Cost of Non-TTIP: a Global Value Chain Approach
}

\author{
Hylke Vandenbussche, William Connell, Wouter Simons ${ }^{1}$
}

\begin{abstract}
What is the cost of non-TTIP for the European Union and the United States? To address this question, this paper develops a network trade model with international sector-level input-output linkages. Our model is entirely general with closed-form solutions and can be used for any trade policy experiment. We use World Input Output Data (WIOD) to simulate the effects of TTIP in terms of value added and employment. We find that a deep TTIP raises European GDP by $1.3 \%$, and US GDP by $0.7 \%$. The largest share of these TTIP gains result from the reduction in Non-Tariff Barriers (NTBs) rather than from the removal of tariffs. The potential gains from TTIP are higher for the EU than for the US. These findings may offer an explanation for the current US stance on TTIP.

JEL Classification: F10, F13, F47, F62
\end{abstract}

Keywords: networks, global value chains, Leontief inverse matrix, TTIP

\footnotetext{
${ }^{1}$ University of Leuven (KU Leuven) - Department of Economics, Naamsestraat 69, B-3000 Leuven, Belgium (corresponding author: hylke.vandenbussche@kuleuven.be; william.connellgarcia@kuleuven.be; wouter.simons@kuleuven.be).

We thank Marcel Timmer, Bart Los, Gaaitzen de Vries, Jozef Konings, Gert Bijnens, Koen Breemersch, Liebrecht De Sadeleer, Elena Zaurino and other participants of a Groningen and Leuven seminar for comments.
} 


\section{Introduction}

The Transatlantic Trade and Investment Partnership (TTIP) refers to a bilateral EU-US free trade agreement that was under consideration during the Obama administration. The purpose was to remove bilateral tariffs and non-tariff barriers on bilateral exports of goods and services ${ }^{2}$. The Trump administration has put the pursuit of TTIP on hold, however. The question that can than be raised by economists is what gains in terms of production and employment are foregone by not concluding TTIP both for the US and for each of the EU-28 countries? To address this question, this paper first develops a novel network trade model with global value chain linkages. The model is then used to predict the effects of the TTIP free trade agreement between the US and the EU. Using existing parameter values from the literature we simulate the trade model using sector-level input-output data.

Production processes are increasingly fragmented across national boundaries. The emergence of global production networks implies that one can no longer consider bilateral trade in isolation when evaluating trade policy or idiosyncratic shocks (Johnson, 2014; Acemoglu et al., 2012). A full assessment of trade shocks requires new models that consider global value chain linkages and trade costs worldwide. A traditional gravity model would not take these international production linkages into account and typically only consider the direct shipments between bilateral trade partners. In this paper, we develop and explicitly solve a network trade model that includes global value chain linkages and overcomes the limitations of a traditional gravity approach. We derive closed-form solutions to allow for comparative statics on changes in trade costs. The model can thus be used for any kind of policy experiment that involves a reduction in trade costs between trade partners such as TTIP.

To illustrate that our network trade model is better suited than traditional gravity models, consider a reduction of bilateral EU-US tariffs on steel and cars after TTIP. When evaluating the impact of such tariff changes on Belgian steel production, a traditional gravity approach would only consider the direct impact of reduced US tariffs on Belgian

\footnotetext{
${ }^{2}$ TTIP also involved opening up government procurement and facilitating bilateral investment but in this paper we only consider the trade aspect.
} 
steel exports to the US. Belgian steel production is also indirectly affected by TTIP, however, as it is used as an input in other domestic and foreign sectors. Indeed, lower US import tariffs on Belgian and German cars increase the US demand for EU cars which raises the intermediate demand for Belgian steel and hence its production. Similarly, US steel production is directly affected by EU tariffs on US steel, as well as indirectly affected by EU tariffs on US cars. Finally, part of the indirect impact of TTIP is due to re-exports, whenever EU steel is embedded in US exports to the EU, or vice versa. A traditional gravity approach would overlook the different types of indirect effects of TTIP on a sector's production. Therefore, the total gains of free trade agreements such as TTIP are incorrectly measured through a traditional gravity approach. The reason is that a sector's production is not only affected by its own tariff change but also by tariff changes in other sectors, whenever there are inter-sectoral production linkages.

We find these indirect effects to be important, particularly in the more upstream sectors. For instance, $74 \%$ of the total impact of a deep TTIP on the Belgian steel sector is due to the indirect channels ${ }^{3}$. The reason is that the steel sector supplies to many other Belgian and EU sectors, which are also affected by TTIP. The indirect impact is smaller in sectors that produce more downstream (final) goods like cars, since these sectors supply less inputs to other sectors, but rather export most of their output directly to the final destination. For the German car industry, for instance, we find that only $8 \%$ of the gains of the TTIP tariff reductions in trading with the US would be indirect. This implies that its direct exports to the US create almost all the benefits of TTIP for the German car sector ${ }^{4}$. This corresponds to the idea that the more upstream and the more central in the supply chain, the larger the indirect production effects of a sector. On average, we find the indirect effects (via other domestic and foreign sectors) of a deep TTIP to amount to $72 \%$ of the total TTIP impact for the EU-28 countries, compared to $60 \%$ for the US. This suggests that production networks in the EU are more closely integrated than in the US. It also suggests that a gravity model at sector-level that does not account for these indirect effects, would

\footnotetext{
${ }^{3}$ For the US (German) steel sector the indirect effects account for $72 \%$ (68\%) of the total TTIP impact.

${ }^{4}$ For the Belgian and US automotive industry, the indirect effects amount to $26 \%$ and $24 \%$ of the total impact, respectively.
} 
seriously bias the effects of TTIP in terms of sector-level production and jobs. In this paper we include both direct and indirect effects, to overcome some of the shortcomings of a traditional gravity approach and the resulting measurement bias.

The model that we develop is probably closest to the one by Noguera [2012] which features indirect exports in a value added setting. While Noguera [2012] considers aggregate trade flows at the country-level, we instead develop a model with both final and intermediate trade flows at the more disaggregate sector-level. This has a number of important advantages. First, trade tariffs vary substantially across sectors, which means that a failure to account for this heterogeneity across sectors may lead to biased results. Second, as intra-industry trade between countries is substantial, it is important to allow two distinct countries to be active in the same sector producing similar goods. Third, our model allows for differences in the trade elasticity across sectors, meaning that consumers (and firms) can react differently to price changes in different sectors. Fourth, it exploits the availability of sector-level data such as the World Input-Ouput Database (WIOD), which allows us to include services in the analysis. This is important given that services are increasingly traded as well as embedded in the exports of goods. Disregarding services would therefore miss an important share of global trade. Finally, as the production linkages between two countries typically differ greatly across sectors, our sectoral approach yields a more precise assessment of the indirect effects of a trade shock and hence of the production and employment effects of tariff changes.

Our theoretical framework features a Cobb-Douglas-CES nest in production as well as in consumption. On the production side, firms produce output with a Cobb-Douglas technology and fixed expenditure shares on labor and a composite intermediate good, taking goods and factor prices as given. The composite intermediate good is a CobbDouglas combination of intermediate goods from all sectors. Each of these sector-specific intermediate goods is a Constant Elasticity of Substitution (CES) aggregate across all the countries the input can be purchased from.

On the consumption side, final consumers derive utility from an aggregate final good, which is a Cobb-Douglas combination of final goods from different sectors. Every sector-specific final good is a CES aggregate across all countries the good can be purchased from. The 
CES nests on the production and the consumption side rely on the Armington assumption, which means that goods produced by different sources are imperfect substitutes simply because of their origin. The way producers and consumers substitute between goods from different countries within a given sector is directly related to the sector's trade elasticity. The Armington assumption closely mimics the input-output data that shows that in reality similar inputs (from the same sector) are purchased from different countries. This is different from a Ricardian approach where every input is sourced from only one particular country, as in Dhingra et al. [2015] and Caliendo et al. [2015]. How much is sourced from each country depends on relative prices, which is a function of the productive efficiency of the supplier and trade costs. Finally, in our analysis we focus on the value-added share in a country-sector's production and the employment associated with it.

The database that we use is the World Input-Output Database (WIOD) ${ }^{5}$, as in Johnson and Noguera [2012], Foster-McGregor and Stehrer [2013], Timmer et al. [2014], Timmer et al. [2015] and others that have investigated inter-sector and international linkages in global value chains. WIOD has a worldwide coverage that allows for the study of production networks covering all countries. Another advantage of using WIOD is that all upstream and downstream sectors can be identified for any sector in the production network, allowing for the construction of input-output linkages. The WIOD database provides the main variables required for our analysis of the impact of a trade shock, i.e. trade flows, value added shares and production input-output linkages. We complement this data with estimates of sectorlevel trade elasticities and employment elasticities that we obtain from the literature.

The novelty of our approach is that we consider all the downstream production and employment effects that stem from a change in domestic value added following a trade shock such as the TTIP free trade agreement. Our approach differs from several studies such as David et al. [2013] who assess US employment effects of Chinese import penetration at the regional level but do not consider the input-output linkages between industries.

\footnotetext{
${ }^{5}$ We use the 2016 release of the World-Input-Output Database (WIOD). This sector-level database provides information about the origin and destination of intermediate and final goods and services in 56 sectors using ISIC Rev.4 for 43 countries between the years 2000 and 2014. Dietzenbacher et al. [2013] describes in great detail the procedure that was followed to construct these World Input-Output Tables.
} 
Other studies are aimed more at identifying the welfare gains and losses from trade policy but focus less on inter-sectoral linkages and intermediates (see Costinot and RodriguezClare, 2013 for an overview). Other papers using input-output data in the context of trade policy have a different focus. Blanchard et al. [2016] show that countries which are more connected in global value chains have lower tariff protection between them. Feenstra and Sasahara [2017] study the impact of U.S. imports from China and U.S. exports to the world on U.S. employment, based on global input-output tables. Dhingra et al. [2017] evaluate Brexit on UK household income levels and Caliendo et al. [2015] assess the welfare effects of NAFTA. Finally, several studies in trade have now shown that gross trade flows do not necessarily reflect the domestic production underlying the trade flow (Koopman et al., 2014; Bernard et al., $2017^{6}$ ), which is why we use value added flows instead.

We consider both a "shallow" and "deep" TTIP scenario, which differ by the extent of trade liberalization between the EU-28 and the US. Under a "shallow TTIP", we assume import tariff to be completely removed. Non-Tariff Barriers (NTBs), which include customs procedures, different regulations and product standards, remain at their current level. Under a deep TTIP, we assume that all tariffs are removed and NTBs are reduced, resulting in greater overall trade cost reductions than under a shallow TTIP ${ }^{7}$. Since both scenarios only differ in the reduction of NTBs, the additional gains from a deep TTIP compared to a shallow TTIP are due completely to the NTB reduction. This allows us to compare the relative importance of NTB versus tariff reductions for the production and employment gains from TTIP.

Our predictions indicate that the EU as a whole stands to gain relatively more than the US, both under a shallow and deep TTIP scenario. For the EU we find an increase in value added production as a percentage of GDP of $0.26 \%$ under a shallow TTIP and up to $1.30 \%$ under a deep TTIP. This corresponds to EU job gains of 234000 jobs for a shallow and

\footnotetext{
${ }^{6}$ Bernard et al. [2017] use firm-level data to show gross export sales can be much larger than domestic production. This micro-level evidence suggests that at the aggregate country-level gross exports can be very different from domestic production.

${ }^{7}$ We limit ourselves to the trade aspect of TTIP, which means we do not consider Foreign Direct Investment (FDI) responses or public procurement responses to larger US-EU trade openness. Our approach is static, i.e. we disregard any dynamic effects of TTIP related to innovation, capital mobility and migration.
} 
over 1 million jobs for a deep TTIP. The gains in value added and jobs differ substantially across all EU-28 member states. The countries that, in relative terms, stand to gain most from TTIP are Ireland, Germany, Belgium and the Netherlands. The potential gains for the US, on the other hand, are relatively lower. A shallow (deep) TTIP would increase US GDP by $0.11 \%$ (0.79\%) and US employment by 49000 jobs (350 000 jobs). The largest share of the deep TTIP gains arise from the reduction of NTBs. The main reason is that tariffs are already historically low and only apply to goods, while NTBs are still relatively high and apply to both goods and services sectors.

The TTIP impact varies across countries due to differences in sectoral composition. As shown by Acemoglu et al. [2012], it is the network centrality of sectors that determines the impact of an aggregate shock through a "cascade effect" in the input-output network. In the TTIP scenarios, we consider different tariff and NTB reductions across sectors, and the propagation of these tariff shocks differs depending on the sectoral composition of the economy considered. A sector that only has a few production linkages with other sectors may not affect aggregate output much even when it faces large drops in trade costs, as opposed to a sector that is very central in the production network. This idea was formalized by Rasmussen [1956]'s forward and backward linkages (see also Miller and Blair, 2009). Our results take this network centrality and the sectoral production linkages into account when estimating the gains in value added and jobs as a result of TTIP.

The remainder of this paper is organized as follows. In Section 2, we develop the theoretical model. In Section 3, we describe the data and methodology used. Section 4 presents the results of our policy experiment, in the form of production and employment gains that could arise from TTIP. Section 5 concludes.

\section{An Input-Output Model of Trade}

In the model below we use superscripts to denote the country-sector of origin and subscripts to denote the country-sector of destination, e.g. the quantity of intermediate steel from

Belgium shipped to the German car industry is denoted by $X_{D E, c a r}^{B E, \text { steel }}$. In general, countries 
are denoted by $i, j$ and $k$ and sectors by $r, s$ and $z^{8}$. Demand for labor by country $k$ 's sector $z$ for example is captured by $L_{k z}$. Throughout this section, upper-case symbols refer to real quantities, whereas lower-case symbols denote their nominal counterparts.

The model is based on the Armington assumption, which means that goods produced by different sources are imperfect substitutes. As a result, within a sector, goods from different countries can coexist in the same destination market, even though their prices may differ as they are determined by the country-sector's marginal production cost and costs of trade with the destination country ${ }^{9}$. Consumers (and firms) in the destination country have a love-for-variety and prefer to consume positive amounts of each available variety.

\subsection{Consumer Demand}

The representative consumer in country $k$ derives utility from consuming quantities of an aggregate final good $F_{k}$ :

$$
U_{k}=F_{k}=\prod_{s=1}^{S}\left[F_{k}^{s}\right]^{\alpha_{k}^{s}}
$$

which is a Cobb-Douglas combination of quantities $F_{k}^{s}$ consumed of final goods from all sectors $s \in S$, with $\alpha_{k}^{s}$ the corresponding share in total expenditures. This sector-specific final good is a CES aggregate across all countries the good can be purchased from,

$$
F_{k}^{s}=\left[\sum_{i=1}^{N}\left(F_{k}^{i s}\right)^{\frac{\sigma_{s}-1}{\sigma_{s}}}\right]^{\frac{\sigma_{s}}{\sigma_{s}-1}}
$$

where $\sigma_{s}>1$ is the elasticity of substitution (for final goods) within sector $s$ between the countries of origin $i \in N^{10}$.

\footnotetext{
${ }^{8}$ We need at least three symbols in the model to denote countries and sectors because input-output models typically consider three nodes in a supply chain: (1) the supplier of intermediate inputs, (2) the final producer and (3) the consumer.

${ }^{9}$ As in Noguera [2012], production and trade costs are the only determinants of prices in our model. This does not imply that firms cannot charge markups. In WIOD, however, we have no information on the underlying firm-level distribution within each sector. The absence of markups in the model is assumed at sectoral level.

${ }^{10}$ For simplicity, we assume this sector-specific elasticity of substitution to be the same across all countries
} $k$. 


\subsection{Producers}

In country $k$ 's sector $z$, output $Y^{k z}$ is produced according to a Cobb-Douglas technology combining labor $L_{k z}$ and intermediate inputs $X_{k z}{ }^{11}$ :

$$
Y^{k z}=\left(L_{k z}\right)^{1-\beta^{k z}}\left(X_{k z}\right)^{\beta^{k z}}
$$

where $\beta^{k z}$ represents the share of intermediate expenditures in total sales of country $k$ 's sector $z$. The intermediate goods composite $X_{k z}$ is a Cobb-Douglas combination of intermediate goods from all sectors $s \in S, X_{k z}^{s}$ :

$$
X_{k z}=\prod_{s=1}^{S}\left[X_{k z}^{s}\right]^{\gamma_{k z}^{s}}
$$

where $X_{k z}^{s}$ denotes the real aggregate demand of intermediates from sector $s$ by country $k$ 's sector $z$, and $\gamma_{k z}^{s}$ is the corresponding share in total expenditures on inputs. The sectorspecific intermediate good $X_{k z}^{s}$ is a CES aggregate across all countries the input can be purchased from:

$$
X_{k z}^{s}=\left[\sum_{i=1}^{N}\left(X_{k z}^{i s}\right)^{\frac{\rho_{s}-1}{\rho_{s}}}\right]^{\frac{\rho_{s}}{\rho_{s}-1}}
$$

where $\rho_{s}>1$ is the elasticity of substitution (for intermediate goods) between the countries of origin within sector $s^{12}$. Note that this nested Cobb-Douglas-CES structure is similar to that of the consumer demand aggregates.

\subsection{Utility and Profit Maximization}

Let $w_{k z}$ denote the price of labor in country $k$ 's sector $z\left(L_{k z}\right)$ and $p^{k z}$ the price of output from $k z\left(Y^{k z}\right)$. Given iceberg-type trade barriers, in order to satisfy country $j$ 's demand of one unit of $k z, k z$ needs to produce $\tau_{j}^{k z}$ units, with $\tau_{j}^{k z}>1$. The price of one unit of

\footnotetext{
${ }^{11}$ Following several standard trade models, we only account for labor as a factor of production. This assumption can be relaxed, for instance by accounting for high-and low skilled labor.

${ }^{12}$ For simplicity, we assume this sector-specific elasticity of substitution to be the same across all countries $k$.
} 
$k z$ 's output in destination $j$ then equals $p_{j}^{k z}=\tau_{j}^{k z} p^{k z}$ accounting for differences in trade costs across destinations $j$. Note that we typically assume there are no barriers to trade within a country, i.e. $\tau_{k}^{k z}=1$.

Firms maximize profits by choosing $L_{k z}$ and $X_{k z}^{i s}$ and households maximize utility choosing $F_{k}^{i s}$ subject to their budget which equals $I_{k}=\sum_{z=1}^{S} w_{k z} L_{k z}$, i.e. their income from supplying labor $L_{k z}$ to each sector $z$ in country $k$. Firms and households take factor price $w_{k z}$ and goods prices $\tau_{j}^{k z} p^{k z}$ as given. This results in the optimal nominal counterparts of real demand (which are denoted by a lower-case symbol and that are obtained by multiplying real demand by the corresponding price). Nominal output of $k z$ is represented by $y^{k z} \equiv p^{k z} Y^{k z}$. The CES price index in country $k$ of final goods from sector $s$ equals $P_{k}^{s}=\left[\sum_{i=1}^{N}\left(p_{k}^{i s}\right)^{1-\sigma_{s}}\right]^{\frac{1}{1-\sigma_{s}}}$. The price of the aggregate intermediate input $X_{k z}$ is given by the Cobb-Douglas price index $P I_{k z}=\prod_{s=1}^{S}\left(P_{k}^{s}\right)_{k z}^{s}$ where $P_{k}^{s}$ is the CES price index in country $k$ for intermediate goods from sector $s$ which we assume, for tractability, to be the same as the corresponding price index for final goods (this implies that $\sigma_{s}=\rho_{s}$ and that the price of a certain good from sector $s$ is the same whether it is sold as an intermediate or a final good ${ }^{13}$. The (FOB) price ${ }^{14}$ of output from $k z$ equals $p^{k z}=\left(\frac{w_{k z}}{1-\beta^{k z}}\right)^{1-\beta^{k z}}\left(\frac{P I_{k z}}{\beta^{k z}}\right)^{\beta^{k z}}$. The optimal nominal demands then equal:

$$
\begin{aligned}
l_{k z} & \equiv w_{k z} L_{k z}=\left(1-\beta^{k z}\right) y^{k z} \\
x_{k z} & \equiv P I_{k z} X_{k z}=\beta^{k z} y^{k z} \\
x_{k z}^{s} & \equiv P_{k}^{s} X_{k z}^{s}=\gamma_{k z}^{s} \beta^{k z} y^{k z} \\
x_{k z}^{i s} & \equiv p_{k}^{i s} X_{k z}^{i s}=\tau_{k}^{i s} p^{i s} X_{k z}^{i s}=\left(\frac{\tau_{k}^{i s} p^{i s}}{P_{k}^{s}}\right)^{1-\sigma_{s}} \gamma_{k z}^{s} \beta^{k z} y^{k z} \\
f_{k}^{i s} & \equiv p_{k}^{i s} F_{k}^{i s}=\tau_{k}^{i s} p^{i s} F_{k}^{i s}=\left(\frac{\tau_{k}^{i s} p^{i s}}{P_{k}^{s}}\right)^{1-\sigma_{s}} \alpha_{k}^{s} \sum_{z=1}^{S}\left(1-\beta^{k z}\right) y^{k z}
\end{aligned}
$$

\footnotetext{
${ }^{13}$ The assumption that firms and consumers share the same price elasticities allows us to substantially simplify the analysis, as in Noguera [2012].

${ }^{14}$ The assumption of perfect pass-through inherent to this theoretical framework is a limiting assumption since pass-through depends on firm size with larger firms having lower pass-through rates (Amiti et al. [2014]). However, in the WIOD data we have no information on the underlying firm size distribution within a sector.
} 


\subsection{Market Clearing}

Let $e_{j}^{k z} \equiv f_{j}^{k z}+\sum_{s=1}^{S} x_{j s}^{k z}$ denote the nominal gross exports from country-sector $k z$ to (the consumer and producers in) country $j$. Market clearing requires

$$
y^{k z}=\sum_{j=1}^{N} e_{j}^{k z}
$$

Following the same logic as in Anderson and Van Wincoop [2003], we derive gravity equations for final and intermediate goods exports, but now at the sector-level. Denote world nominal output by $y^{w}$ and country-sector $k z$ 's share in world output by $\theta^{k z} \equiv y^{k z} / y^{w}$. Substituting Equations (6) and (7) into Equation (8) allows to solve for prices $p^{i s}$. Substituting these into the price index $P_{k}^{s}$ and plugging the resulting expression for $P_{k}^{s}$ into (6) and (7) results in the following gravity equations for intermediate and final bilateral exports and equilibrium price indices:

$$
\begin{aligned}
x_{j s}^{k z} & =\frac{y^{k z} \gamma_{j s}^{z} \beta^{j s} y^{j s}}{y^{w}}\left(\frac{\tau_{j}^{k z}}{\Pi^{k z} P_{j}^{z}}\right)^{1-\sigma_{z}} \\
f_{j}^{k z} & =\frac{y^{k z} \alpha_{j}^{z} \sum_{s=1}^{S}\left(1-\beta^{j s}\right) y^{j s}}{y^{w}}\left(\frac{\tau_{j}^{k z}}{\Pi^{k z} P_{j}^{z}}\right)^{1-\sigma_{z}} \\
P_{j}^{z} & =\left[\sum_{k=1}^{N} \theta^{k z}\left(\frac{\tau_{j}^{k z}}{\Pi^{k z}}\right)^{1-\sigma_{z}}\right]^{\frac{1}{1-\sigma z}} \\
\Pi^{k z} & =\left[\sum_{j=1}^{N} \phi_{j}^{z}\left(\frac{\tau_{j}^{k z}}{P_{j}^{z}}\right)^{1-\sigma_{z}}\right]^{\frac{1}{1-\sigma z}}
\end{aligned}
$$

where $\phi_{j}^{z}=\sum_{s=1}^{S} \theta^{j s}\left(\gamma_{j s}^{z} \beta^{j s}+\alpha_{j}^{z}\left(1-\beta^{j s}\right)\right)$ is a measure of the importance of goods from sector $z$ for producers and consumers in country $j$. It takes into account (i) the dependence of producers in all sectors $s$ in country $j$ on intermediates from sector $z$ through $\theta^{j s} \gamma_{j s}^{z} \beta^{j s}$ and (ii) the importance of goods from sector $z$ in the final demand by households in country $j$ (through $\alpha_{j}^{z}$ ) and the total income these households earn in all sectors $s$ in $j$ (through $\left.\theta^{j s}\left(1-\beta^{j s}\right)\right)$.

Equation (9) relates bilateral intermediate trade between firms in country-sector $k z$ and country-sector $j s$ to (i) the economic masses of source and destination relative to the world, 
(ii) the importance of inputs in the destination's production $\left(\beta^{j s}\right)$ and the importance of sector $z$ goods within these inputs $\left(\gamma_{j s}^{z}\right)$, (iii) the bilateral trade costs between countries $k$ and $j$ in sector $z\left(\tau_{j}^{k z}\right)$, and (iv) outward and inward multilateral resistance terms $\left(\Pi^{k z}\right.$ and $P_{j}^{z}$ ). Similarly, Equation (10) relates bilateral final goods trade between firms in countrysector $k z$ and the consumers in country $j$ to (i) the economic masses of source $\left(y^{k z}\right)$ and destination $\left(\sum_{s=1}^{S}\left(1-\beta^{j s}\right) y^{j s}\right)^{15}$ relative to the economic mass of the world $\left(y^{w}\right)$, (ii) the importance of sector $z$ final goods in the destination's consumption $\left(\alpha_{j}^{z}\right)$, (iii) the bilateral trade costs between countries $k$ and $j$ in sector $z\left(\tau_{j}^{k z}\right)$, and (iv) outward and inward multilateral resistance terms $\left(\Pi^{k z}\right.$ and $\left.P_{j}^{z}\right)$.

\subsection{Input-Output Production Linkages}

Dividing both sides of Equation (9) by $y^{j s}$ we obtain the technical coefficient $a_{j s}^{k z}$ or "dollar's worth of inputs from $k z$ per dollar's worth of output of $j s "$ :

$$
\frac{x_{j s}^{k z}}{y^{j s}} \equiv a_{j s}^{k z}=\frac{y^{k z} \gamma_{j s}^{z} \beta^{j s}}{y^{w}}\left(\frac{\tau_{j}^{k z}}{\Pi^{k z} P_{j}^{z}}\right)^{1-\sigma_{z}}
$$

Plugging the technical coefficients into the market clearing in condition in (8), we have

$$
\begin{aligned}
y^{k z} & =\sum_{j=1}^{N}\left(\sum_{s=1}^{S} x_{j s}^{k z}+f_{j}^{k z}\right) \\
& =\sum_{j=1}^{N} \sum_{s=1}^{S} a_{j s}^{k z} y^{j s}+\sum_{j=1}^{N} f_{j}^{k z}
\end{aligned}
$$

which can be summarized for all countries and sectors as

$$
\boldsymbol{Y}=\boldsymbol{A} \boldsymbol{Y}+\sum_{j=1}^{N} \boldsymbol{f}_{j}
$$

\footnotetext{
${ }^{15}$ This expression reflects the fact that consumers in country $j$ get their income from supplying labor to all sectors $s$.
} 
where

$$
\boldsymbol{Y}=\left[\begin{array}{c}
y^{1,1} \\
y^{1,2} \\
\vdots \\
y^{N, S}
\end{array}\right] ; \quad \boldsymbol{A}=\left[\begin{array}{ccccc}
a_{1,1}^{1,1} & a_{1,2}^{1,1} & a_{1,3}^{1,1} & \ldots & a_{N, S}^{1,1} \\
a_{1,1}^{1,2} & a_{1,2}^{1,2} & a_{1,3}^{1,2} & \ldots & a_{N, S}^{1,2} \\
\vdots & \vdots & \vdots & \ddots & \vdots \\
a_{1,1}^{N, S} & a_{1,2}^{N, S} & a_{1,3}^{N, S} & \ldots & a_{N, S}^{N, S}
\end{array}\right] ; \quad \boldsymbol{f}_{\boldsymbol{j}}=\left[\begin{array}{c}
f_{j}^{1,1} \\
f_{j}^{1,2} \\
\vdots \\
f_{j}^{N, S}
\end{array}\right]
$$

where $\boldsymbol{f}_{j}$ is the $(S * N) \times 1$ vector of country $j$ 's final demands and $\boldsymbol{A}$ the $\left(S^{*} N\right) \times\left(S^{*} N\right)$ global bilateral input-output matrix at the sectoral level. The system in Equation (12) can be written as

$$
(\square-\boldsymbol{A}) \boldsymbol{Y}=\sum_{j=1}^{N} \boldsymbol{f}_{j}
$$

with $\square$ the $\left(S^{*} N\right) \times\left(S^{*} N\right)$ identity matrix. If $(\square-\boldsymbol{A})$ can be inverted, we can find the solution for nominal output as

$$
\boldsymbol{Y}=(\mathbb{\square}-\boldsymbol{A})^{-1} \sum_{j=1}^{N} \boldsymbol{f}_{j}=\boldsymbol{L} \sum_{j=1}^{N} \boldsymbol{f}_{j}
$$

where $\boldsymbol{L}$ is known as the Leontief inverse matrix. Each element $L_{i s}^{k z}$ of $\boldsymbol{L}$ is the Leontief coefficient that measures the total of dollars worth of country-sector $k z$ goods required to meet 1 dollar worth of $i s^{\prime}$ final demand. This value combines $k z$ goods used as inputs in $i s$ directly as well as $k z$ goods used as inputs in other industries which then also produce inputs for $i s$. Using this, we can obtain country $k$ 's nominal output in sector $z$ as

$$
\begin{aligned}
y^{k z} & =\sum_{i=1}^{N} \sum_{s=1}^{S} L_{i s}^{k z} \sum_{j=1}^{N} f_{j}^{i s} \\
& =\sum_{i=1}^{N} \sum_{s=1}^{S} L_{i s}^{k z} \sum_{j=1}^{N}\left(\frac{y^{i s} \alpha_{j}^{s} \sum_{r=1}^{S}\left(1-\beta^{j r}\right) y^{j r}}{y^{w}}\left(\frac{\tau_{j}^{i s}}{\Pi^{i s} P_{j}^{s}}\right)^{1-\sigma_{s}}\right)
\end{aligned}
$$

where we substituted the gravity relation from Equation (10) for the final value $f_{j}^{i s}$ flowing from country-sector $i s$ to the consumer in country $j$. Finally, we can transform this into value added production. For this purpose, we assume that the value added share of a country-sector's production is the part that is generated by its labor. Looking back at the 
production function in (3), the value created by country-sector $k z$ after accounting for the intermediates used is captured by the share of labor $1-\beta^{k z}$. Hence, following Noguera [2012] we find the value added embodied in $k z$ 's nominal production $y^{k z}$ as $\left(1-\beta^{k z}\right) y^{k z}$ where $1-\beta^{k z} \equiv v^{k z}$ is the value added to output ratio. The total value added production by $k z$ can thus be written as

$$
v a^{k z}=v^{k z} \sum_{i=1}^{N} \sum_{s=1}^{S} L_{i s}^{k z} \sum_{j=1}^{N} f_{j}^{i s}
$$

This value added production (and the jobs depending on it) might be severely impacted in the case of a trade shock, which is the subject of the next section.

\subsection{Creation of a Free Trade Agreement}

In this section, we examine the impact of the creation of a free trade agreement on a country-sector's value added production. We know that an import tariff imposed on a specific good will not only affect the producer of the good, but also the suppliers of goods and services whose output is used as an input in the production of the good. This implies that when the US agrees to lower its import tariff on, say, German cars, the Belgian steel sector which supplies inputs to the German car industry will also be affected, even if the US tariff on Belgian steel does not change. This channel is missing in a traditional gravity approach but is captured by our methodology. The impact of a trade shock can be examined by considering what would happen when the variable trade costs $(\tau)$ change. Our interest lies in the change $\mathrm{d} v a^{k z}$ in country-sector $k z$ 's value added production, which we find to equal

$$
\begin{aligned}
\mathrm{d} v a^{k z} & =-v^{k z} \sum_{i=1}^{N} \sum_{s=1}^{S}\left(\sigma_{s}-1\right) L_{i s}^{k z} \sum_{j=1}^{N} \hat{\tau}_{j}^{i s}\left\{f_{j}^{i s}+\sum_{r=1}^{S} x_{j r}^{i s}\right\} \\
& =-v^{k z} \sum_{i=1}^{N} \sum_{s=1}^{S}\left(\sigma_{s}-1\right) L_{i s}^{k z} \sum_{j=1}^{N} \hat{\tau}_{j}^{i s} e_{j}^{i s}
\end{aligned}
$$

from which we can derive the following general result. Rising trade costs reduce bilateral

trade flows $e_{j}^{i s}$ between any country-sector $i s$ and $j$. As $k z$ has an interest $L_{i s}^{k z}$ in each of 
these bilateral flows, $v a^{k z}$ will decrease as well. The drop depends on the magnitude of the change in relative trade costs $\hat{\tau}_{j}^{i s}$ between $i s$ and $j$ and the corresponding trade elasticity $\sigma_{s}$.

In Equation (17), we defined $\hat{\tau}_{j}^{i s} \equiv \frac{\mathrm{d} \tau_{j}^{i s}}{\tau_{j}^{i s}}-\frac{\mathrm{d} \Pi^{i s}}{\Pi^{i s}}-\frac{\mathrm{d} P_{j}^{s}}{P_{j}^{s}}$ as the proportionate change in tariffs $\tau_{j}^{i s}$ relative to the proportionate changes in the multilateral resistance (MR) terms. When examining trade policy, it is important to take into account that the multilateral resistance (MR) terms will change along with the tariffs. Therefore, Equation (17) not only examines the impact of $\frac{\mathrm{d} \tau_{j}^{i s}}{\tau_{j}^{i s}}$ but also that of $\frac{\mathrm{d} \Pi^{i s}}{\Pi^{i s}}$ and $\frac{\mathrm{d} P_{j}^{s}}{P_{j}^{s}}$. As it is relative tariffs that matter rather than absolute tariffs to determine a country's global competitiveness, individual tariff changes should be compared with changes in the average tariff, which is captured by the multilateral resistance terms. Suppose, for instance, that the US tariff on Belgian goods goes down with $3 \%$ after TTIP. However, if the US reduces its tariffs on all its other trading partners with $3 \%$ as well, the Belgian products did not become cheaper in relative terms. What matters is the tariff change a producer faces relative to the tariff change its competitors face.

After TTIP, the only countries that are likely to face reduced costs of trading with the US are the EU-28 ${ }^{16}$, whereas the tariffs the US imposes on its other trading partners such as Canada will not change. This means that Canadian goods will become relatively more expensive for the US, even though the US tariffs on Canadian imports do not change. The reason is that TTIP actually increases (i.e. $\hat{\tau}_{U S}^{C A, s}>0$ ) the "relative" CA-US trade costs compared to EU-US trade costs. As a result, some trade will be diverted from the CA-US to the EU28-US. The MR changes $\frac{\mathrm{d} \Pi^{i s}}{\Pi^{i s}}$ and $\frac{\mathrm{d} P_{j}^{s}}{P_{j}^{s}}$ are essential for trade diversion to happen. We can see this by disentangling the change $\hat{\tau}_{j}^{i s}$ into its different components, namely the

\footnotetext{
${ }^{16}$ For simplicity, we still consider the UK as a member of the EU in this analysis. A hard Brexit, however, is likely to have an impact on the effects of TTIP, as the UK is an important trade partner of the US. Since the outcome of the Brexit trade talks is still uncertain, we abstain from making any predictions and continue to consider the UK as an EU member with access to the European Single Market.
} 
tariff change and the MR changes:

$$
\mathrm{d} v a^{k z}=-\underbrace{v^{k z} \sum_{i=1}^{N} \sum_{s=1}^{S}\left(\sigma_{s}-1\right) L_{i s}^{k z} \sum_{j=1}^{N} \frac{\mathrm{d} \tau_{j}^{i s}}{\tau_{j}^{i s}} e_{j}^{i s}}_{\text {trade creation effect }}+\underbrace{v^{k z} \sum_{i=1}^{N} \sum_{s=1}^{S}\left(\sigma_{s}-1\right) L_{i s}^{k z} \sum_{j=1}^{N}\left[\frac{\mathrm{d} \Pi^{i s}}{\Pi^{i s}}+\frac{\mathrm{d} P_{j}^{s}}{P_{j}^{s}}\right] e_{j}^{i s}}_{\text {trade diversion effect }}
$$

Equation (18) shows that the change in $k z$ 's value added production after a change in trade costs $\tau$ is a combination of a "trade creation effect" $(+)$ as a result of lower tariffs and a "trade diversion effect" (-) caused by the change in the multilateral resistance terms. The results can be summarized in the following proposition:

Proposition 1: The change in $k z$ 's value added production after a trade shock depends on two effects. First, the positive "trade creation effect" indicates that the gain in $v a^{k z}$ depends on $k z$ 's connection with each exporting country-sector $i s$. The rise in $v a^{k z}$ will be greater, (i) the higher is the trade elasticity in sector $s$ (higher $\left(\sigma_{s}-1\right)$ ); (ii) the greater is the decrease in protection imposed by $j$ on sector $s$ goods originating in country $i$ (higher negative change $\frac{\mathrm{d} \tau_{j}^{i s}}{\tau_{j}^{i s}}$ ); (iii) the greater is the production interlinkage of $k z$ with is (higher $L_{i s}^{k z}$ ) and (iv) the stronger is the direct bilateral trade relation in both final and intermediate goods between $i$ and $j$ in sector $s$ (higher $e_{j}^{i s}$ ). Second, these positive effects will be mitigated through the "trade diversion" channel, as some of $k z$ 's production was used in exports that are diverted away from after the trade shock.

Equation (18) characterizes all the different channels through which a trade shock can affect a sector's output $v a^{k z}$. It is clear that the impact of a trade shock such as TTIP on a given sector can be very different depending on a number of determinants that vary by sector. Strong production interlinkages (high $L$ ) with a large exporting sector (high $e$ ) do not necessarily lead to large production gains (through the "trade creation effect") in case this sector produces highly differentiated goods (making it insensitive to price changes, i.e. $\sigma$ is low) or experiences only minor tariff decreases (small $\frac{\mathrm{d} \tau}{\tau}$ ). Accounting for this sectoral heterogeneity gives a more accurate picture of the potential impact of trade policy.

The focus of our analysis lies in the production and employment effects of a trade shock such as the formation of TTIP. Our framework is less well equipped to answer questions 
about welfare or productivity gains from trade liberalization. Our sector-level approach does not account for firm-level heterogeneity within sectors. Given that we do not have information on the underlying firm-size distribution per sector, our framework does not allow us to observe reallocation effects following trade liberalization. Melitz [2003] showed that trade liberalization reallocates market shares from less to more productive firms, resulting in average and aggregate productivity gains. Moreover, the heterogeneous firm literature provides evidence of an endogenous response of within-firm productivity to trade liberalization. Trefler [2004] examines the rise in labor productivity of Canadian manufacturing after the Canada-US Free Trade Agreement and finds an industry-level increase of $5.8 \%$ in labor productivity due to the FTA and a $7.4 \%$ increase at the plant-level. Both the reallocation productivity gains and the within-firm productivity improvements are absent from our framework. Our primary focus lies in production network linkages at the sector-level. Since we have no information on sector-level productivity gains, our results are ceteris paribus, i.e. holding productivity constant, and are therefore likely to underestimate the full impact of the TTIP trade agreement.

In the next section, we apply our framework to the specific TTIP trade shock. We compute the possible production effects of the US-EU trade deal, in which both parties lower their bilateral trade costs such as tariffs and Non-Tariff Barriers (NTBs) $)^{17}$.

\section{Data and Methodology}

This section takes the model to the data and simulates the effects of different scenarios of TTIP using input-output data from WIOD. The starting point is Equation (18), which computes $k z$ 's potential value added gains $\mathrm{d} v a^{k z}$ as a combination of a trade creation and diversion effect, where the latter derives from the changes in multilateral resistance

\footnotetext{
${ }^{17}$ Our analysis only captures the static effects of a trade shock and it does not include dynamic effects such as access to foreign markets, firm investment and innovation, capital mobility and migration. In terms of the time horizon, we assume all effects to occur immediately after the TTIP agreement is signed. However, it should be noted that it can take some time for our simulated outcomes to arise. Especially non-tariff barriers (NTBs) can have a lagged effect.
} 
(MR) terms. These MR terms are not observable, and not controlling for them in gravity estimation is what Baldwin and Taglioni [2006] call "the gold medal of classic gravity model mistakes". Empirically, there are several ways to deal with the issue of MR, see for instance Anderson and Van Wincoop [2003], Baier and Bergstrand [2009] and Novy [2013]. Hummels [1999] and Feenstra [2015] suggest to control for MR using directional (exporter and importer) fixed effects in a gravity model based on past data series. However, in our analysis of the cost of a non-TTIP, where we simulate the model to engage in future predictions, the inclusion of fixed effects is not an option. The empirical findings in the literature on the magnitude of the trade diversion effect of import tariffs are ambiguous but seem to suggest that trade diversion effects tend to be small ${ }^{18}$. In order to divert trade, new business contacts have to be established, new contracts negotiated and so on, which takes some time to materialize. In our assessment of TTIP, we therefore concentrate on the short-run effects and restrict Equation (18) to the first term that measures the "trade creation effect". This is the first-order trade effect, which captures the main effects of the TTIP's tariff changes ${ }^{19}$. The increase in country-sector $k z$ 's value added production as a

\footnotetext{
${ }^{18}$ There appears to be no consensus in the literature on the magnitude of trade diversion effects. Dai et al. [2014] use manufacturing trade data for 64 countries and find that Free Trade Agreements (FTAs) divert trade, particularly on the import-side. However, Magee [2008] using different gravity specifications estimates of the trade diversion effects of regional agreements to be small and their significance to depend on the specification used. Similarly, Soloaga and Wintersb [2001] found evidence of export diversion in a minority of FTAs i.e. only 2 out of 9 FTAs analyzed had substantial trade diversion. Dhingra et al. [2017] estimates the potential gains by non-EU countries arising from the reduced trade between the EU-27 and the UK. The non-EU gains turn out to be very small, approximately between 0.01 and $0.02 \%$ of GDP. Therefore, the mitigation effects of trade diversion are likely to be small.

${ }^{19}$ Not accounting for trade diversion further implies that our framework does not capture so-called "beggar-thy-neighbor"-effects. This refers to the effects of trade policy on domestic production at the expense of foreign production imported from the trading partners. In this sense, the case of non-TTIP may hold some benefits for domestic producers as their output would be higher under non-TTIP than in the event of TTIP when some domestic production is substituted by foreign output.
} 
result of reduced costs of trade between the US and the EU will thus be approximated by

$$
\mathrm{d} v a^{k z} \approx-\underbrace{v^{k z} \sum_{i \in E U} \sum_{s=1}^{S}\left(\sigma_{s}-1\right) \frac{\mathrm{d} \tau_{U S}^{E U, s}}{\tau_{U S, s}^{E U, s}} L_{i s}^{k z} e_{U S}^{i s}}_{\text {EU-US trade creation effect }}-\underbrace{v^{k z} \sum_{s=1}^{S}\left(\sigma_{s}-1\right) \frac{\mathrm{d} \tau_{E U}^{U S, s}}{\tau_{E U, s}^{U S}} L_{U S, s}^{k z} \sum_{j \in E U} e_{j}^{U S, s}}_{\text {US-EU trade creation effect }}
$$

Equation (19) reveals that $k z$ 's value added production will go up as a result of increased EU-US as well as US-EU trade. Lower trade costs boost transatlantic flows in both directions, and the impact on $k z$ 's production is therefore twofold. The data needed to calibrate Equation (19) to obtain the value added production gains are discussed in the next section.

\subsection{Value Added Production Gains}

In order to obtain an estimate of the value added gains, Equation (19) indicates that five key variables are needed. The five determinants in this equation are retrieved from various sources: (i) the value added to output share $v^{k z}$, the Leontief coefficient $L_{i s}^{k z}$ and the direct trade flows $e_{U K}^{i s}$ are variables from WIOD; (ii) the trade elasticities at sector-level $\sigma_{s}$ are borrowed from the literature and (iii) the change in trade barriers $\tau$ is derived from two potential TTIP scenarios. The job gains that correspond with the gains in value added from TTIP are obtained from Eurostat (OECD) data on EU-28 (US) sector-level employment, using sectoral employment elasticities from the literature.

\subsubsection{Input-Output Data}

The World Input-Output Database (WIOD) contains detailed information on the global value chains of 44 world countries and 56 sectors $^{20}$. The latest available year is 2014, which we use in our analysis.

For each country-sector, WIOD provides its total production, the inputs it needs from other country-sectors and how much of its output is used by other country-sectors in their

\footnotetext{
${ }^{20}$ Alternatively, other databases used in the literature are the "Global Trade Analysis Project Database", "OECD Input-Output Tables" or the "WTO-OECD TiVA Database.
} 
production process. The first variable that we obtain from WIOD is the value added share of country-sector $k z$ 's production, $v^{k z}$. This captures the value added, obtained as gross output minus gross intermediate inputs, per unit of gross output. We also obtain the Leontief coefficients, $L_{i s}^{k z}$ from WIOD, which are obtained using Equation (14). In addition, again from WIOD we obtain the direct trade flows $e_{j}^{i s}$ from country is to country $j$, which are obtained by summing exports from $i s$ that are destined to country $j$ to satisfy its final and intermediate demand.

\subsubsection{Trade Elasticities}

Changes in value added at the sector-level further depend on a sector-level trade elasticity. A trade elasticity measures the proportionate increase in demand after a $1 \%$ decrease in trade costs. In terms of TTIP, it captures the idea that lower US tariffs and Non-Tariff Barriers (NTBs) will decrease the price of EU products in the US (and vice versa), which will boost US consumers' demand of EU goods. In the model, this is captured by the elasticity of substitution $\sigma_{s}$ in sector $s$, from which the trade elasticity is derived as $\sigma_{s}-1$.

The literature has shown that trade elasticities typically vary both across countries and sectors. For example, Imbs and Méjean [2017] use product-level gross export flows between 1995-2004 to estimate trade elasticities, based on a multi-sector model developed by Arkolakis et al. [2012] and Costinot and Rodriguez-Clare [2013]. They confirm that there is considerable heterogeneity in trade elasticities across countries and sectors. Using aggregate data, they find that the average trade elasticity within the EU countries is -2.98 with a minimum of -2.11 for Germany and a maximum of -4.83 for Greece $^{21}$. Using more disaggregated data, they find that, within countries, trade elasticities also vary across products and consequently across sectors. Using their estimates, we find that Germany has an average elasticity across 11 manufacturing sectors of -5.1 , with a median of -4.7

\footnotetext{
${ }^{21}$ For more information, see Table 4 in Imbs and Méjean [2017].
} 
and maximum and minimum of -11.1 and -3.2 , respectively ${ }^{22}$. In order to allow for the heterogeneity across sectors that is present in the theoretical framework, we use the average trade elasticies across countries at a sectoral level given that Imbs and Méjean [2017] do not report estimates of trade elasticities for every EU country-sector. In this way, we obtain elasticities for 16 different manufacturing sectors. For the remaining sectors we assign a trade elasticity of -4 which is a lower-end estimate of the trade elasticities reported in earlier literature. However, given that we analyze trade in value added rather than gross flows and that our data are at sector-level and not at product-level, we prefer to use the lower-end estimate of the trade elasticity. Therefore, the simulation results that we obtain can be regarded as lower bound estimates ${ }^{23}$. We assume complete pass-through of tariffs into domestic prices (congruent with the model). While our results depend on the choice of the trade elasticity, what has to be kept in mind is that our results vary linearly with the trade elasticity i.e. doubling the trade elasticity in every sector, doubles the value added gains from TTIP. Hence, results depend monotonically on the trade elasticity parameter.

\subsubsection{Potential TTIP Scenarios}

The gains in value added from Equation (19) hinge on the decrease in trade barriers. We consider two TTIP scenarios, namely a "shallow" and a "deep" Transatlantic Trade and Investment Partnership, referring to different reductions in the tariffs and NTBs on trade between the EU and the US.

The current level of tariffs between both trading partners are the Most Favored Nations (MFN) tariffs at product-level, according to World Trade Organization (WTO) rules. For both the EU and the US as a reporting country, we compute the unweighted average

\footnotetext{
${ }^{22}$ In our analysis, we use a sectoral aggregation at 2 digit in Nace Rev. 2. For this reason, we use the Reference and Management of Nomenclatures tables (RAMON) provided by Eurostat to find the correspondence of the estimates provided by Imbs and Méjean [2017] who use ISIC3 as their product classification.

${ }^{23}$ Other trade elasticities estimates in the literature confirm this heterogeneity. Baier and Bergstrand [2001] use trade data to estimate a demand elasticity of -6.43, while Broda et al. [2006] use ten-digit HS data to obtain price elasticities of around -12. A recent paper by Coşar et al. [2016] uses a trade elasticity of -5.66. Ossa [2015] estimates sector level trade elasticities which range between -1.54 and -25.05 .
} 
applied MFN tariff across products within each sector (as classified in WIOD). The tariff per sector for EU goods trade to the US and vice versa are shown in Figure 1.

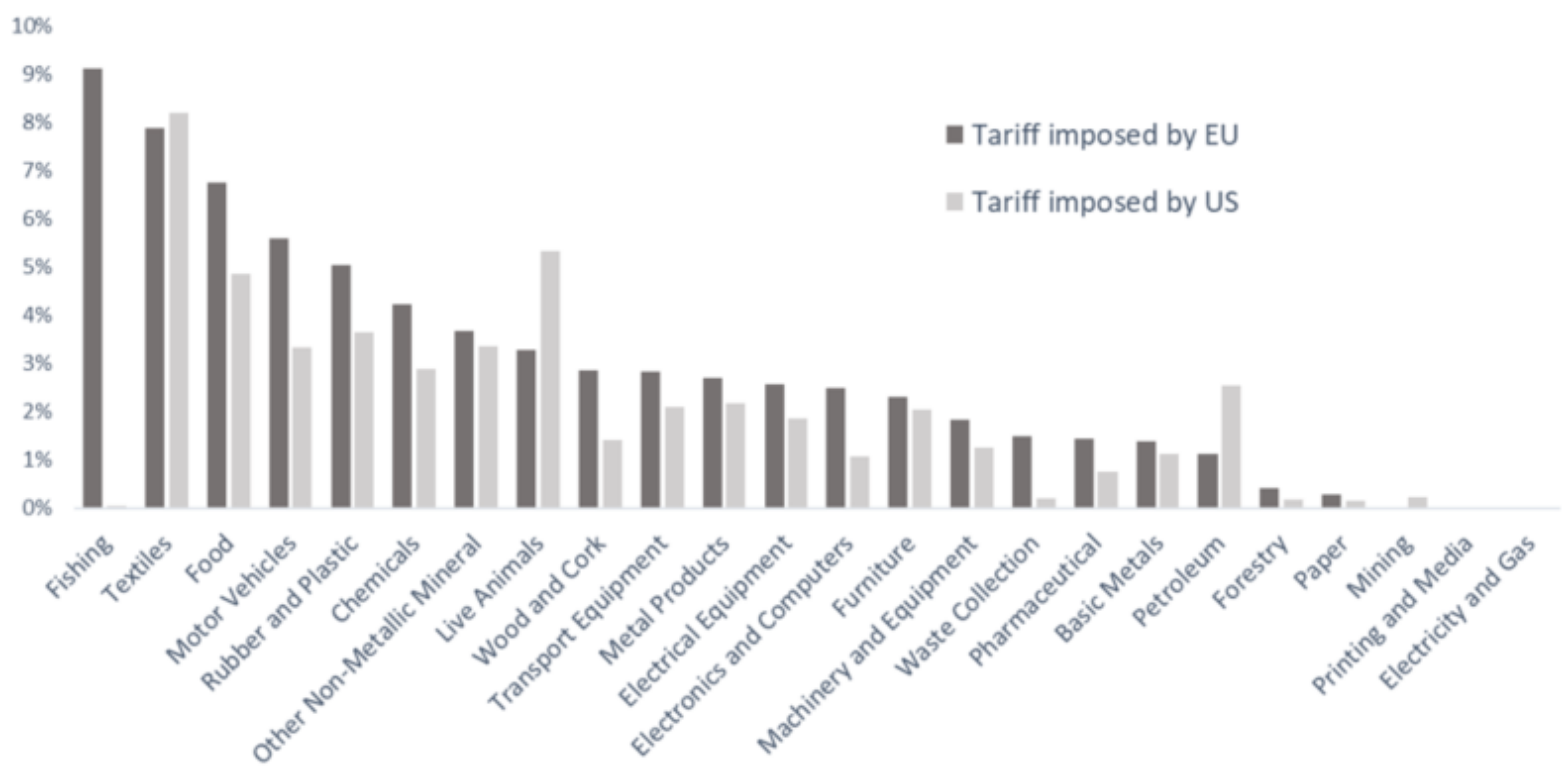

Figure 1: Average MFN tariff imposed by EU and US

Note: Information on the current tariffs applied are collected using the WTO Integrated Data Base (IDB). This database contains information on the applied tariffs at the standard codes of the Harmonized System (HS) for all the WTO Members. In this exercise, we use the Reference and Management of Nomenclatures (RAMON) correspondence tables to classify the equivalent Combined Nomenclature (CN) to the respective CPA 2008 code.

The current level of NTBs are obtained from Berden et al. [2009], which gives the tariff equivalent of the current non-tariff barriers to trade between the EU and the US and vice versa for a subset of sectors. These barriers include "border measures" (such as customs procedures) and "behind-the-border measures" that result from domestic regulations and standards. Part of these regulatory differences between trade partners are driven by language, geography and culture and refer to frictions that cannot be eliminated. Even in the extreme case that the US and the EU negotiate a very deep TTIP agreement that eliminates all existing barriers to trade, part of these NTBs (around 50\% according to Berden et al., 2009) will remain. We follow Berden et al. [2009] in designing our scenarios 
and allow only for reductions in NTBs that are feasible. The reducible share in NTBs differs across sectors and depends on the direction of the trade flow (US-EU or EU-US trade), which we also account for.

Using the information on tariffs and NTBs, we design two types of the transatlantic trade agreement. Under a "shallow TTIP", we assume negotiations to affect only the level of the tariff by completely removing them, while NTBs remain at their current level. A deep TTIP is assumed to remove all tariffs and reduce the NTBs by the full reducible part (Berden et al., 2009). Note that since both scenarios only differ in the reduction of NTBs, the additional gains from a deep TTIP compared to a shallow TTIP should be attributed completely to the NTB reduction. This allows us to get an idea of the relative importance of the NTB and tariff reductions for the production and employment gains from TTIP.

Table 1 summarizes the shallow and deep TTIP scenarios.

Table 1: Remaining trade costs under TTIP

\begin{tabular}{c|cc}
\hline & shallow TTIP & deep TTIP \\
\hline Tariffs & $0 \%$ & $0 \%$ \\
Non-tariff barriers & current level & maximally reduced \\
\hline Note: Information on NTBs is obtained from Berden et al. [2009].
\end{tabular}

\subsection{Employment Gains}

Based on Equation (19), we use the data discussed above to obtain the total value added production increase $\mathrm{d} v a^{k z}$ in country $k$ 's sector $z$. To arrive at employment effects, we need an employment elasticity. This elasticity measures the proportionate rise in employment after a $1 \%$ increase in value added production. In theory, Hamermesh [1986] argued that a production function characterized by constant returns to scale (as in our framework) features an elasticity of 1 . However, this differs from empirical evidence. Konings and Murphy [2006] use European firm level data and report employment elasticities with respect to value added for manufacturing and non-manufacturing sectors below 1 . They find the range of average employment elasticities between 0.57 and 0.72 in manufacturing 
sectors and 0.33 in non-manufacturing sectors. We use the lower bound of these sectoral estimates to obtain the effect of TTIP on EU and US employment. This implies that for every $1 \%$ increase in domestically produced value added, we assume employment to go up by $0.57 \%$ in manufacturing and $0.33 \%$ in non-manufacturing sectors. Similar to the trade elasticities, the TTIP results on employment depend linearly on the choice of the employment elasticity. Thus, once we have obtained the relative rise in employment from the increase in production, we can compute the absolute number of jobs gained by multiplying by the country-sector's total employment base ${ }^{24}$.

\section{Results}

\subsection{The Cost of non-TTIP}

We present and discuss the results on the gains of TTIP (or the cost of non-TTIP) in this section. The effects of the formation of a free trade agreement are assumed to materialize immediately, i.e. we do not consider any transition period. As such, our results are the outcome of a static analysis. As explained before, we account for two different scenarios: (i) a shallow TTIP that removes all tariffs that currently apply to EU-US trade and (ii) a deep TTIP that additionally eliminates NTBs to the extent that is possible. We present both value added production and employment effects in the two scenarios for all countries involved (EU-28 and the US). The results are summarized in Tables 2 and 3. It has to be kept in mind that our analysis has been entirely carried out at the sectoral level, whereas in the tables we have aggregated results at the country-level.

For value added, the results can be found in Table 2. For a shallow TTIP, we find modest economic gains. A shallow TTIP would increase EU GDP ${ }^{25}$ by $0.26 \%$, which is significantly more than the $0.11 \%$ increase in US GDP. There is strong heterogeneity within the EU-28, however. The country that stands to gain most from a shallow TTIP is Ireland $(0.62 \%$

\footnotetext{
${ }^{24}$ Throughout the analysis, we assume that any job lost in the US is not going to move to the EU-28 and vice versa.

${ }^{25}$ GDP or Total Value Added (TVA) for each country is obtained using the WIOD database.
} 
increase in GDP), whereas for countries like Cyprus and Greece there is not so much at stake (0.03-0.04\% gain in GDP).

Similar conclusions can be drawn for the deep TTIP scenario in Table 2. The potential gain of a deep TTIP for the aggregate EU-28 (1.30\% of GDP) is again higher than for the US $(0.79 \%)$. Within the European Union, the potential value added gains vary significantly by country. Ireland experiences considerable gains (3.75\% increase in GDP), followed by Germany (1.82\%), Belgium (1.57\%) and the Netherlands (1.57\%).

Table 3 summarizes the employment results for both TTIP scenarios. A shallow TTIP creates 234000 jobs in the EU (0.11\% of total EU employment) and 49000 jobs in the US $(0.04 \%$ of total). In relative terms, the job gains are highest for Italy with $0.20 \%$ employment increase (corresponding to 44500 jobs). A deep TTIP potentially creates more than 1 million EU jobs, increasing total employment by $0.49 \%$. In the US, job gains

are ca. 350000 jobs or $0.30 \%$. Ireland would now be the largest beneficiary with more than a $1 \%$ increase in employment (20 000 jobs), potentially explained by the large impact the elimination of NTBs under a deep TTIP would have on the services-oriented Irish economy.

\subsection{Heterogeneity Across Sectors}

There are large differences in the impact of TTIP between the different sectors. This section investigates the sector-level heterogeneity and its causes.

Table 4 lists the sector that stands to gain most from a deep TTIP in each country. Sectors can differ depending on whether we express gains in terms of value added or employment. The reason is that the value added contribution per worker differs across sectors. The same increase in value added can lead to different employment effects in different sectors. For example, in terms of value added the German "Motor Vehicles" sector gains most from a deep TTIP, while in terms of employment it is "Machinery \& Equipment". For the EU-28 as a whole, a deep TTIP increases both production and employment most in the "Machinery \& Equipment" industry. In the US, the sectors that gain most are "Chemicals" (in value added terms) and Administrative \& Support activities (in terms of employment). 
The sector-level heterogeneity in terms of TTIP impact depends heavily on the magnitude of the tariff change, but also the sector-level trade elasticity as well as the network centrality of the sector. The current average MFN tariffs per sector for EU goods trade to the US and vice versa were shown in Figure 1 before. In the event of a TTIP we assume these tariffs to reduce to zero in every sector, which for some sectors such as Textiles involves a large tariff reduction, while for other sectors such as Paper products involves only a small tariff change. Clearly, the larger the tariff reduction, the stronger the increase in production that the model predicts (see Equation (19)), depending also on the sector-level trade elasticities which are reported in Table 5 along with the employment elasticity.

Another important determinant of the sectoral heterogeneity in the TTIP impact is the network centrality of a sector within the input-output production network. This is illustrated in Table 6, where we contrast the indirect production effects of a deep TTIP for an upstream sector like steel (basic metals) with the indirect impact for a downstream sector like cars (motor vehicles). For each country, the indirect impact is expressed as a percentage of the total impact and measures the share of the country-sector's total value added production gain from a deep TTIP that is due to an increase in exports of other domestic or foreign sectors once the trade agreement is signed. For most of the countries involved, the upstream sector steel displays much larger indirect production effects from TTIP than the downstream car sector. The reason is that steel is used as an input in many other sectors, therefore in the case of TTIP it is not just the tariff change in steel that affects steel production but also tariff changes in other sectors. On the other hand, the indirect effects are small in the car sector, suggesting that most of the production effects in this sector are due to the change in tariffs on cars induced by TTIP.

To improve understanding of the relative importance of the indirect impact of a trade agreement, Figure 2 below displays the shares of direct and indirect impact of a deep TTIP for a number of sectors in Germany and the US. The sole purpose of selecting these sectors is to illustrate the difference in direct versus indirect impact of TTIP between more downstream and more upstream sectors. The first six sectors on the left of Figure 2 are downstream sectors that produce final goods which are closer to the consumer, such as motor vehicles, furniture, textiles and food. For these downstream sectors, the direct 
impact (represented by the dark bar) clearly constitutes the lion's share of the impact of deep TTIP, as explained in the steel and car example. The last four sectors at the right end of Figure 2 can be regarded as more upstream sectors whose output is used as an input in the production process of other industries, which is the case for basic metals and mining for instance. We clearly see that for those upstream sectors, the impact of a deep TTIP is largely indirect, as around $70 \%$ of the value added production gain is due to an increase in exports of other domestic or foreign sectors after the trade agreement. Finally, the difference between Germany and the US appears to be quite small in most sectors, which confirms the idea that there is more heterogeneity across sectors than across countries in terms of the importance of the indirect network effects in the total impact of a free trade agreement.

Figure 2 suggests that a network approach like ours is especially relevant to capture the indirect effects that are mainly situated in the upstream sectors. In upstream sectors, a gravity approach would only consider direct trade flows at sector-level to a final destination and would thus miss out a lot of the production effects in the case of a free trade agreement. Our network approach aims to overcome this limitation by also considering the production and employment effects in a sector that result from its indirect linkages to other sectors. 


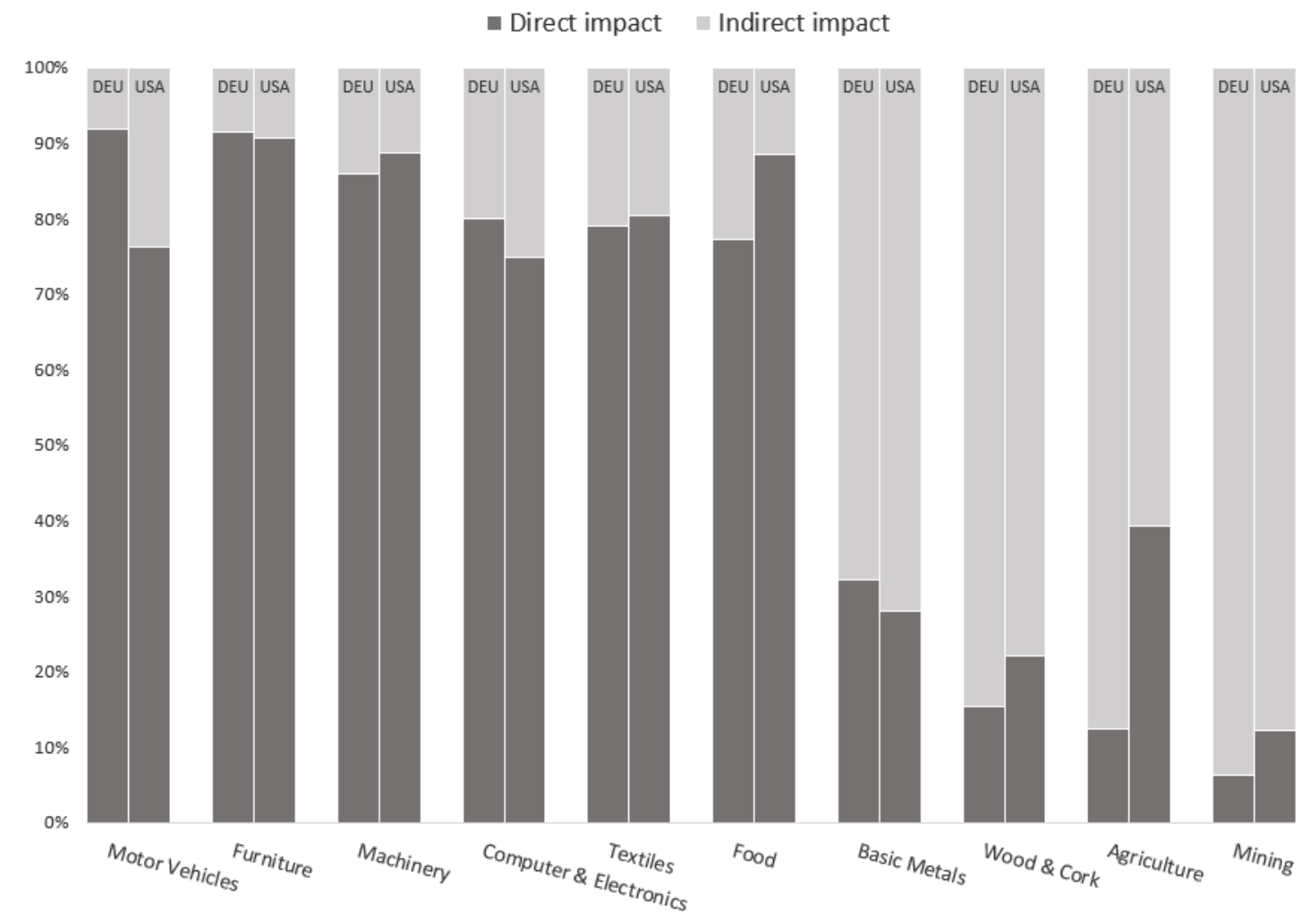

Figure 2: Share of direct and indirect impact of deep TTIP on German and US sectors

Note: the indirect impact in a country-sector is computed as the share of the value added production gain that is due to an increase in exports of other domestic or foreign sectors after a deep TTIP agreement. The direct impact is the share of the value added production gain that is due to the sector's own increased exports.

\subsection{Importance of Tariffs and NTB Reduction}

This section briefly discusses the importance of the different types of liberalization under TTIP, by investigating which type of trade barrier matters more in TTIP, namely tariffs or Non-Tariff Barriers (NTBs). In other words, do tariff reductions or NTB reductions cause the largest TTIP gains? To answer this question, we can simply look at the difference between the shallow and the deep TTIP gains. Our shallow TTIP scenario is defined as an agreement to completely eliminate tariffs while leaving NTBs unchanged. Under deep TTIP, we assume tariffs are completely eliminated, and in addition NTBs are reduced. As 
a result, the additional gains under a deep TTIP compared to a shallow TTIP are caused by the reduction in NTBs.

This NTB reduction turns out to be the most important determinant of the deep TTIP gains. Based on the estimates of the gains under a shallow and deep TTIP in Table 2, we can assess the relative importance of tariff reductions versus NTB reductions. For an individual EU country like Germany, we find that tariff reductions account for $22 \%$ of the TTIP gains, while NTB reductions account for the remaining $78 \%{ }^{26}$. For the EU as a whole, tariff reductions account for $20 \%$ of TTIP gains, while NTB reductions account for the remaining $80 \%$. For the US, tariff liberalization accounts for $13 \%$ and NTB reductions account for $87 \%$ of the TTIP gains. These numbers clearly indicate that NTB liberalization is much more important in the case of TTIP and this is true for every trade partner involved in TTIP as well as every sector.

The first reason as to why the NTB reduction generates most of the gains from TTIP is that, currently, the tariff equivalent of the Non-Tariff Barriers to transatlantic trade is significantly higher than the prevailing MFN tariffs (see Berden et al., 2009). Another reason is that NTBs apply both to goods and services, whereas tariffs are only imposed on goods trade, which increases the importance of reducing NTBs compared to tariffs.

\footnotetext{
${ }^{26}$ The total value added gain under a shallow TTIP is 14.7 billion dollars for Germany, while the gain amounts to 65.7 billion dollars under a deep TTIP. The effects that are due to the tariff reductions can thus be computed as $14.7 / 65.7=0.22$. The remaining $78 \%(1-0.22)$ is caused by the NTB reduction.
} 


\section{Conclusion}

In this paper we develop and explicitly solve a trade model with worldwide sector-level input-output linkages in production. The model allows us to separately identify all the channels through which tariff changes operate. This results in a new network trade model that overcomes the limitations of a traditional gravity approach and that derives closed form solutions which allow for comparative statics on tariff changes.

A traditional gravity model is often used to estimate the effects of tariff changes on trade flows which are then used to infer changes in the sector's production. We argue here that this approach does not account for production changes that arise from input-output linkages. Tariff changes in other sectors also need to be taken into account whenever a sector's output is used as inputs by other domestic and foreign sectors. This is especially relevant when a sector is well-connected in the network and its inputs are used by many other sectors. Including these indirect production effects in the analysis results in more accurate estimates of a free trade agreement which typically involves lower tariffs in many sectors. Hence, an important insight from our analysis is that indirect production effects are stronger whenever a sector is more upstream. The measurement bias arising from traditional gravity analysis to assess the economic gains from bilateral free trade agreements such as TTIP is therefore larger whenever a sector is higher up in the value chain and supplies to many other sectors.

Using World Input Output Data (WIOD), we simulate our model both under a shallow TTIP that removes all tariffs that currently apply to EU-US trade, and a deep TTIP, that additionally eliminates all removable non-tariff barriers. We find that TTIP can boost bilateral trade between the EU and US, as well as increase production and employment in all trade partners. Our sector-level input-ouput approach indicates that the EU-28 as a whole stands to gain relatively more from TTIP than the US, both in the case of a shallow and deep TTIP. One of the main reasons for this difference in gains is the more closely integrated EU-28 production network both across sectors and countries. Another important finding that arises from our analysis is that the largest share of TTIP gains come from the reduction of Non-Tariff Barriers (NTBs) as opposed to tariff reductions. 
We find strong heterogeneity in TTIP gains across EU member states. The EU country that stands to gain most from TTIP is Ireland, followed by Germany, Belgium and the Netherlands. This heterogeneity derives from the sectoral composition of these economies and on the centrality of their key sectors in the EU production network. This confirms Acemoglu et al. [2012], who find it is the sector's network centrality that determines the impact of an aggregate shock through a "cascade effect" in the input-output network. A sector that faces large tariff reductions may not have strong aggregate effects if it is not well connected to other sectors, whereas a sector facing small tariff changes can have a large aggregate impact if it is central in the economy and supplies to many other sectors. Hence from a macro point of view, this granular approach to free trade agreements is important. Our analysis is one of the first to take the network centrality and the input-output sectoral linkages into account when predicting the potential gains in production and employment of a free trade agreement such as TTIP. 


\section{References}

Daron Acemoglu, Vasco M Carvalho, Asuman Ozdaglar, and Alireza Tahbaz-Salehi. The network origins of aggregate fluctuations. Econometrica, 80(5):1977-2016, 2012.

Mary Amiti, Oleg Itskhoki, and Jozef Konings. Importers, exporters, and exchange rate disconnect. The American Economic Review, 104(7):1942-1978, 2014.

James E Anderson and Eric Van Wincoop. Gravity with gravitas: a solution to the border puzzle. The American Economic Review, 93(1):170-192, 2003.

Costas Arkolakis, Arnaud Costinot, and Andrés Rodríguez-Clare. New trade models, same old gains? The American Economic Review, 102(1):94-130, 2012.

Scott L Baier and Jeffrey H Bergstrand. The growth of world trade: tariffs, transport costs, and income similarity. Journal of international Economics, 53(1):1-27, 2001.

Scott L Baier and Jeffrey H Bergstrand. Bonus vetus OLS: A simple method for approximating international trade-cost effects using the gravity equation. Journal of International Economics, 77(1):77-85, 2009.

Richard Baldwin and Daria Taglioni. Gravity for dummies and dummies for gravity equations. Technical report, National Bureau of Economic Research, 2006.

Koen G Berden, Joseph Francois, Mr Martin Thelle, Mr Paul Wymenga, and Ms Saara Tamminen. Non-tariff measures in eu-us trade and investment-an economic analysis. Report Number OJ 2007/S 180, 219493, 2009.

Andrew B Bernard, Emily J Blanchard, Ilke Van Beveren, and Hylke Vandenbussche. Carry-Along Trade. Review of Economic Studies, forthcoming, 2017.

Emily J Blanchard, Chad P Bown, and Robert C Johnson. Global supply chains and trade policy. Technical report, National Bureau of Economic Research, 2016.

Christian Broda, Joshua Greenfield, and David Weinstein. From groundnuts to globalization: A structural estimate of trade and growth. Technical report, National Bureau of Economic Research, 2006. 
Lorenzo Caliendo, Maximiliano Dvorkin, and Fernando Parro. The impact of trade on labor market dynamics. Technical report, National Bureau of Economic Research, 2015.

A. Kerem Coşar, Nezih Guner, and James Tybout. Firm dynamics, job turnover, and wage distributions in an open economy. The American Economic Review, 106(3):625$663,2016$.

Arnaud Costinot and Andres Rodriguez-Clare. Trade theory with numbers: Quantifying the consequences of globalization. Technical report, National Bureau of Economic Research, 2013.

Mian Dai, Yoto V Yotov, and Thomas Zylkin. On the trade-diversion effects of free trade agreements. Economics Letters, 122(2):321-325, 2014.

H David, David Dorn, and Gordon H Hanson. The China syndrome: Local labor market effects of import competition in the United States. The American Economic Review, 103 (6):2121-2168, 2013.

Swati Dhingra, Gianmarco Ottaviano, Thomas Sampson, et al. Should we stay or should we go? The economic consequences of leaving the EU. CEP Election Analysis Paper, $22,2015$.

Swati Dhingra, Hanwei Huang, Gianmarco IP Ottaviano, João Paulo Pessoa, Thomas Sampson, and John Van Reenen. The costs and benefits of leaving the EU: Trade effects. 2017.

Erik Dietzenbacher, Bart Los, Robert Stehrer, Marcel Timmer, and Gaaitzen De Vries. The construction of world input-output tables in the WIOD project. Economic Systems Research, 25(1):71-98, 2013.

Robert C Feenstra. Advanced international trade: theory and evidence. Princeton university press, 2015.

Robert C Feenstra and Akira Sasahara. The China Shock, exports and US employment: A global input-output analysis. 2017. 
Neil Foster-McGregor and Robert Stehrer. Value added content of trade: A comprehensive approach. Economics Letters, 120(2):354-357, August 2013.

Daniel S Hamermesh. The demand for labor in the long run. Handbook of labor economics, 1:429-471, 1986.

David L Hummels. Toward a geography of trade costs. 1999.

Jean Imbs and Isabelle Méjean. Trade elasticities. Review of International Economics, 25 (2):383-402, 2017.

R. C. Johnson. Five facts about value-added exports and implications for macroeconomics and trade research. The Journal of Economic Perspectives, 28(2):119-142., 2014.

Robert C Johnson and Guillermo Noguera. Accounting for intermediates: Production sharing and trade in value added. Journal of International Economics, 86(2):224-236, 2012.

Jozef Konings and Alan Patrick Murphy. Do multinational enterprises relocate employment to low-wage regions? Evidence from European multinationals. Review of World Economics, 142(2):267-286, 2006.

Robert Koopman, Zhi Wang, and Shang-Jin Wei. Tracing value-added and double counting in gross exports. The American Economic Review, 104(2):459-494, 2014.

Christopher SP Magee. New measures of trade creation and trade diversion. Journal of International Economics, 75(2):349-362, 2008.

Marc J Melitz. The impact of trade on intra-industry reallocations and aggregate industry productivity. Econometrica, 71(6):1695-1725, 2003.

Ronald E Miller and Peter D Blair. Input-output analysis: foundations and extensions. Cambridge University Press, 2009.

Guillermo Noguera. Trade costs and gravity for gross and value added trade. Job Market Paper, Columbia University, 2012. 
Dennis Novy. Gravity redux: measuring international trade costs with panel data. Economic Inquiry, 51(1):101-121, 2013.

Ralph Ossa. Why trade matters after all. Journal of International Economics, 97(2): $266-277,2015$.

P. Nørregaard Rasmussen. Studies in Inter-sectoral Relations, 14, 1956.

Isidro Soloaga and L Alan Wintersb. Regionalism in the nineties: What effect on trade? The North American Journal of Economics and Finance, 12(1):1-29, 2001.

Marcel P Timmer, Abdul Azeez Erumban, Bart Los, Robert Stehrer, and Gaaitzen J de Vries. Slicing up global value chains. The Journal of Economic Perspectives, 28(2): 99-118, 2014.

Marcel P Timmer, Erik Dietzenbacher, Bart Los, Robert Stehrer, and Gaaitzen J de Vries. An illustrated user guide to the world input-output database: the case of global automotive production. Review of International Economics, 23(3):575-605, 2015.

Daniel Trefler. The long and short of the canada-us free trade agreement. American Economic Review, 94(4):870-895, 2004. 


\section{Tables}

Table 2: Total gain in Value Added from TTIP

\begin{tabular}{c|cc|cc|} 
& \multicolumn{2}{|c|}{ Shallow TTIP } & \multicolumn{2}{c|}{ Deep TTIP } \\
\cline { 2 - 5 } Country & $($ million $\$)$ & (\% of total VA $)$ & $($ million $\$)$ & $(\%$ of total VA) \\
& $(1)$ & $(2)$ & $(3)$ & $(4)$ \\
\hline AUT & 1184 & $0.29 \%$ & 5463 & $1.35 \%$ \\
BEL & 1225 & $0.24 \%$ & 7883 & $1.57 \%$ \\
BGR & 83 & $0.16 \%$ & 387 & $0.74 \%$ \\
CYP & 7 & $0.03 \%$ & 52 & $0.24 \%$ \\
CZE & 556 & $0.28 \%$ & 2522 & $1.27 \%$ \\
DEU & 14683 & $0.41 \%$ & 65649 & $1.82 \%$ \\
DNK & 639 & $0.20 \%$ & 3432 & $1.09 \%$ \\
ESP & 1795 & $0.14 \%$ & 8649 & $0.67 \%$ \\
EST & 35 & $0.14 \%$ & 191 & $0.77 \%$ \\
FIN & 487 & $0.20 \%$ & 2903 & $1.17 \%$ \\
FRA & 4439 & $0.17 \%$ & 23880 & $0.90 \%$ \\
GBR & 5446 & $0.19 \%$ & 33435 & $1.20 \%$ \\
GRC & 86 & $0.04 \%$ & 529 & $0.25 \%$ \\
HRV & 88 & $0.17 \%$ & 417 & $0.82 \%$ \\
HUN & 415 & $0.33 \%$ & 1859 & $1.47 \%$ \\
IRL & 1456 & $0.62 \%$ & 8873 & $3.75 \%$ \\
ITA & 7430 & $0.38 \%$ & 30194 & $1.53 \%$ \\
LTU & 83 & $0.18 \%$ & 519 & $1.13 \%$ \\
LUX & 69 & $0.11 \%$ & 346 & $0.57 \%$ \\
LVA & 35 & $0.12 \%$ & 185 & $0.64 \%$ \\
MLT & 8 & $0.08 \%$ & 46 & $0.47 \%$ \\
NLD & 1862 & $0.22 \%$ & 12982 & $1.57 \%$ \\
POL & 840 & $0.16 \%$ & 4135 & $0.81 \%$ \\
PRT & 386 & $0.18 \%$ & 1561 & $0.73 \%$ \\
ROU & 291 & $0.16 \%$ & 1309 & $0.70 \%$ \\
SVK & 222 & $0.23 \%$ & 932 & $0.96 \%$ \\
SVN & 94 & $0.21 \%$ & 421 & $0.93 \%$ \\
SWE & 1179 & $0.22 \%$ & 6259 & $1.17 \%$ \\
\hline EU-28 & $\mathbf{4 5} \mathbf{1 2 4}$ & $\mathbf{0 . 2 6 \%}$ & $\mathbf{2 2 5} \mathbf{0 1 3}$ & $\mathbf{1 . 3 0 \%}$ \\
USA & $\mathbf{1 8 5 6 4}$ & $\mathbf{0 . 1 1 \%}$ & $\mathbf{1 3 7} \mathbf{2 6 8}$ & $\mathbf{0 . 7 9 \%}$ \\
\hline
\end{tabular}

Note: See the Appendix for a list of the country name abbreviations. 
Table 3: Total gain in Employment from TTIP

\begin{tabular}{|c|c|c|c|c|}
\hline \multirow[b]{2}{*}{ Country } & \multicolumn{2}{|c|}{ Shallow TTIP } & \multicolumn{2}{|c|}{ Deep TTIP } \\
\hline & $\begin{array}{l}\text { (jobs) } \\
(1)\end{array}$ & $\begin{array}{c}(\% \text { of total EMP) } \\
(2)\end{array}$ & $\begin{array}{c}\text { (jobs) } \\
(3) \\
\end{array}$ & $\begin{array}{c}(\% \text { of total EMP) } \\
(4)\end{array}$ \\
\hline AUT & 5039 & $0.12 \%$ & 23598 & $0.55 \%$ \\
\hline BEL & 4057 & $0.09 \%$ & 25683 & $0.57 \%$ \\
\hline BGR & 3139 & $0.09 \%$ & 12895 & $0.38 \%$ \\
\hline CYP & 74 & $0.02 \%$ & 363 & $0.11 \%$ \\
\hline $\mathrm{CZE}$ & 6822 & $0.13 \%$ & 30333 & $0.59 \%$ \\
\hline DEU & 64349 & $0.15 \%$ & 289791 & $0.69 \%$ \\
\hline DNK & 1877 & $0.07 \%$ & 9831 & $0.36 \%$ \\
\hline ESP & 10303 & $0.06 \%$ & 46588 & $0.27 \%$ \\
\hline $\mathrm{EST}$ & 388 & $0.06 \%$ & 1917 & $0.32 \%$ \\
\hline FIN & 1927 & $0.08 \%$ & 11367 & $0.46 \%$ \\
\hline FRA & 19460 & $0.07 \%$ & 99035 & $0.36 \%$ \\
\hline GBR & 22647 & $0.07 \%$ & 132951 & $0.43 \%$ \\
\hline GRC & 714 & $0.02 \%$ & 3849 & $0.10 \%$ \\
\hline HRV & 1379 & $0.09 \%$ & 6176 & $0.39 \%$ \\
\hline HUN & 5594 & $0.13 \%$ & 23870 & $0.57 \%$ \\
\hline IRL & 3524 & $0.18 \%$ & 20431 & $1.06 \%$ \\
\hline ITA & 44478 & $0.20 \%$ & 174114 & $0.77 \%$ \\
\hline LTU & 808 & $0.06 \%$ & 4043 & $0.31 \%$ \\
\hline LUX & 125 & $0.04 \%$ & 607 & $0.17 \%$ \\
\hline LVA & 34 & $0.01 \%$ & 209 & $0.05 \%$ \\
\hline MLT & 37 & $0.03 \%$ & 178 & $0.12 \%$ \\
\hline NLD & 6230 & $0.07 \%$ & 47547 & $0.55 \%$ \\
\hline POL & 12041 & $0.08 \%$ & 55978 & $0.36 \%$ \\
\hline PRT & 4992 & $0.11 \%$ & 16660 & $0.38 \%$ \\
\hline $\mathrm{ROU}$ & 6673 & $0.08 \%$ & 26169 & $0.30 \%$ \\
\hline SVK & 2340 & $0.11 \%$ & 9712 & $0.44 \%$ \\
\hline SVN & 888 & $0.10 \%$ & 3877 & $0.42 \%$ \\
\hline SWE & 3702 & $0.08 \%$ & 19677 & $0.44 \%$ \\
\hline EU-28 & 233638 & $0.11 \%$ & 1097446 & $0.49 \%$ \\
\hline USA & 48905 & $0.04 \%$ & 347164 & $0.30 \%$ \\
\hline
\end{tabular}

Note: See the Appendix for a list of the country name abbreviations.

Note: Employment data in Eurostat is missing for some sectors in the following countries: Estonia, Latvia, Lithuania, Luxembourg, Malta and Sweden. Therefore, the presented employment results for these countries will likely underestimate the true impact. 
Table 4: Sectors with highest potential gains from a deep TTIP

\begin{tabular}{|c|c|c|c|c|}
\hline \multirow[b]{2}{*}{ Country } & \multicolumn{4}{|c|}{ Sector Nace Rev.2 } \\
\hline & Value Added (VA) & $(2)$ & $\begin{array}{l}\text { Employment (EMP) } \\
(3)\end{array}$ & $(4)$ \\
\hline AUT & Machinery \& Equipment & $\mathrm{C} 28$ & Machinery \& Equipment & $\mathrm{C} 28$ \\
\hline BEL & Chemicals & $\mathrm{C} 20$ & Legal \& Accounting & M69-M70 \\
\hline BGR & Textiles & $\mathrm{C} 13-\mathrm{C} 15$ & Crop \& Animal production & A01 \\
\hline CYP & Water transport & H50 & Fishing & A03 \\
\hline $\mathrm{CZE}$ & Machinery \& Equipment & $\mathrm{C} 28$ & Metal products & $\mathrm{C} 25$ \\
\hline $\mathrm{DEU}$ & Motor vehicles & $\mathrm{C} 29$ & Machinery \& Equipment & $\mathrm{C} 28$ \\
\hline DNK & Pharmaceutical & $\mathrm{C} 21$ & Machinery \& Equipment & $\mathrm{C} 28$ \\
\hline ESP & Chemicals & $\mathrm{C} 20$ & Crop \& Animal production & A01 \\
\hline $\mathrm{EST}$ & Administrative \& Support & $\mathrm{N}$ & Furniture & $\mathrm{C} 31-\mathrm{C} 32$ \\
\hline FIN & Machinery \& Equipment & $\mathrm{C} 28$ & Machinery \& Equipment & $\mathrm{C} 28$ \\
\hline FRA & Administrative \& Support & $\mathrm{N}$ & Administrative \& Support & $\mathrm{N}$ \\
\hline GBR & Machinery \& Equipment & $\mathrm{C} 28$ & Machinery \& Equipment & $\mathrm{C} 28$ \\
\hline GRC & Wholesale trade & G46 & Crop \& Animal production & A01 \\
\hline HRV & Metal products & $\mathrm{C} 25$ & Metal products & $\mathrm{C} 25$ \\
\hline HUN & Motor vehicles & $\mathrm{C} 29$ & Motor vehicles & $\mathrm{C} 29$ \\
\hline IRL & Food & $\mathrm{C} 10-\mathrm{C} 12$ & Food & $\mathrm{C} 10-\mathrm{C} 12$ \\
\hline ITA & Textiles & $\mathrm{C} 13-\mathrm{C} 15$ & Textiles & $\mathrm{C} 13-\mathrm{C} 15$ \\
\hline LTU & Petroleum products & $\mathrm{C} 19$ & Furniture & C31-C32 \\
\hline LUX & Wholesale trade & G46 & Administrative \& Support & $\mathrm{N}$ \\
\hline LVA & Food & $\mathrm{C} 10-\mathrm{C} 12$ & Administrative \& Support & $\mathrm{N}$ \\
\hline MLT & Administrative \& Support & $\mathrm{N}$ & Administrative \& Support & $\mathrm{N}$ \\
\hline NLD & Administrative \& Support & $\mathrm{N}$ & Administrative \& Support & $\mathrm{N}$ \\
\hline POL & Wholesale trade & G46 & Crop \& Animal production & $\mathrm{A} 01$ \\
\hline PRT & Textiles & $\mathrm{C} 13-\mathrm{C} 15$ & Textiles & $\mathrm{C} 13-\mathrm{C} 15$ \\
\hline $\mathrm{ROU}$ & Machinery \& Equipment & $\mathrm{C} 28$ & Textiles & $\mathrm{C} 13-\mathrm{C} 15$ \\
\hline SVK & Motor vehicles & $\mathrm{C} 29$ & Metal products & $\mathrm{C} 25$ \\
\hline SVN & Metal products & $\mathrm{C} 25$ & Metal products & $\mathrm{C} 25$ \\
\hline SWE & Machinery \& Equipment & $\mathrm{C} 28$ & Machinery \& Equipment & $\mathrm{C} 28$ \\
\hline EU-28 & Machinery \& Equipment & $\mathrm{C28}$ & Machinery \& Equipment & $\mathrm{C28}$ \\
\hline USA & Chemicals & $\mathrm{C20}$ & Administrative \& Support & $\mathbf{N}$ \\
\hline
\end{tabular}

Note: See the Appendix for a list of the country name abbreviations and sector codes.

Note: Which sector gains most depends on whether we express gains in terms of value added or employment. The reason is that the value added contribution per worker can differ dramatically across sectors. Given that we express the gains in absolute numbers, this means that the same increase in value added might lead to different employment effects in different sectors.

Note: Employment data in Eurostat is missing for some sectors in the following countries: Estonia, Latvia, Lithuania, Luxembourg, Malta and Sweden. 
Table 5: Trade and employment elasticity for manufacturing and services sectors

\begin{tabular}{c|cc|} 
Sector & $\begin{array}{c}\text { Trade } \\
\text { elasticity }\end{array}$ & $\begin{array}{c}\text { Employment } \\
\text { elasticity }\end{array}$ \\
\hline Manufacturing & & \\
\hline Live Animals (A01) & -4.0 & 0.57 \\
Forestry (A02) & -4.0 & 0.57 \\
Fishing (A03) & -4.0 & 0.57 \\
Mining and Quarrying (B) & -4.0 & 0.57 \\
Food Product (C10-C12) & -6.3 & 0.57 \\
Textiles (C13-C15) & -11.9 & 0.57 \\
Wood and Cork (C16) & -5.0 & 0.57 \\
Paper Products (C17) & -4.9 & 0.57 \\
Printing and Media (C18) & -5.1 & 0.57 \\
Petroleum Products (C19) & -7.8 & 0.57 \\
Chemicals (C20) & -5.7 & 0.57 \\
Pharmaceutical (C21) & -5.7 & 0.57 \\
Rubber and Plastic (C22) & -5.1 & 0.57 \\
Other Non-Metallic (C23) & -4.9 & 0.57 \\
Basic Metals (C24) & -6.1 & 0.57 \\
Metal pProducts (C25) & -8.1 & 0.57 \\
Electronics \& Computers (C26) & -11.3 & 0.57 \\
Electrical Equipment (C27) & -4.0 & 0.57 \\
Machinery \& Equipment (C28) & -9.9 & 0.57 \\
Motor Vehicles (C29) & -4.0 & 0.57 \\
Transport Equipment (C30) & -4.0 & 0.57 \\
Furniture (C31-C32) & -7.4 & 0.57 \\
Repair of Machinery (C33) & -12.8 & 0.57 \\
\hline Services & -4.0 & 0.33 \\
\hline
\end{tabular}

Note: Trade elasticities for manufacturing sectors were obtained from Imbs and Méjean [2017]. To the manufacturing sectors not reported in Imbs and Méjean [2017], we assign a trade elasticity of -4 which is a lower-end estimate of the trade elasticities reported in earlier literature. Since there are no reliable trade elasticity estimates available for the non-manufacturing (services) sectors, we assign the same lower bound trade elasticity of -4 to these sectors, see the last row in the table. The employment elasticity is derived from Konings and Murphy [2006] and equals 0.57 for goods and 0.33 for services. 
Table 6: Share of indirect in total impact of deep TTIP in metal and motor vehicles sector

\begin{tabular}{c|cc|}
\multirow{2}{*}{ Country } & \multicolumn{2}{|c|}{ Share of indirect impact } \\
\cline { 2 - 3 } AUT & Basic Metals & Motor Vehicles \\
\hline BEL & $67 \%$ & $27 \%$ \\
BGR & $74 \%$ & $26 \%$ \\
CYP & $87 \%$ & $52 \%$ \\
CZE & $100 \%$ & $94 \%$ \\
DEU & $63 \%$ & $79 \%$ \\
DNK & $68 \%$ & $8 \%$ \\
ESP & $81 \%$ & $55 \%$ \\
EST & $80 \%$ & $27 \%$ \\
FIN & $58 \%$ & $67 \%$ \\
FRA & $62 \%$ & $29 \%$ \\
GBR & $70 \%$ & $59 \%$ \\
GRC & $36 \%$ & $11 \%$ \\
HRV & $62 \%$ & $42 \%$ \\
HUN & $65 \%$ & $62 \%$ \\
IRL & $84 \%$ & $36 \%$ \\
ITA & $80 \%$ & $70 \%$ \\
LTU & $66 \%$ & $22 \%$ \\
LUX & $92 \%$ & $97 \%$ \\
LVA & $59 \%$ & $73 \%$ \\
MLT & $92 \%$ & $87 \%$ \\
NLD & $92 \%$ & $51 \%$ \\
POL & $63 \%$ & $56 \%$ \\
PRT & $91 \%$ & $80 \%$ \\
ROU & $79 \%$ & $58 \%$ \\
SVK & $66 \%$ & $65 \%$ \\
SVN & $90 \%$ & $37 \%$ \\
SWE & $75 \%$ & $71 \%$ \\
USA & $57 \%$ & $26 \%$ \\
\hline
\end{tabular}

Note: See the Appendix for a list of the country name abbreviations.

Note: the indirect impact in a country-sector is computed as the share of the value added production gain that is due to an increase in exports of other domestic or foreign sectors after a deep TTIP agreement. 


\section{Appendix}

Table 7: Countries and ISO-3 Codes

\begin{tabular}{|cc|cc|}
\hline Country Name & Code (ISO-3) & Country Name & Code (ISO-3) \\
\hline Austria & AUT & Hungary & HUN \\
Belgium & BEL & Ireland & IRL \\
Bulgaria & BGR & Italy & ITA \\
Cyprus & CYP & Lithuania & LTU \\
Czech Republic & CZE & Luxembourg & LUX \\
Germany & DEU & Latvia & LVA \\
Denmark & DNK & Malta & MLT \\
Spain & ESP & Netherlands & NLD \\
Estonia & EST & Poland & POL \\
Finland & FIN & Portugal & PRT \\
France & FRA & Romania & ROU \\
United Kingdom & GBR & Slovakia & SVK \\
Greece & GRC & Slovenia & SVN \\
Croatia & HRV & Sweden & SWE \\
\hline
\end{tabular}


Table 8: Nace Rev. 2 Codes \& Labels

\begin{tabular}{|c|c|c|c|}
\hline \multicolumn{2}{|r|}{ Goods } & \multicolumn{2}{|r|}{ Services } \\
\hline Nace Rev.2 & Sector Legend (Short) & Nace Rev.2 & Sector Legend (Short) \\
\hline A01 & Live Animals & $\mathrm{F}$ & Construction \\
\hline $\mathrm{A} 02$ & Forestry & G45 & Wholesale and retail trade \\
\hline A03 & Fishing & G46 & Wholesale trade \\
\hline B & Mining and quarrying & G47 & Retail trade \\
\hline $\mathrm{C} 10-\mathrm{C} 12$ & Food Product & H49 & Land \& Pipeline transport \\
\hline $\mathrm{C} 13-\mathrm{C} 15$ & Textiles & H50 & Water transport \\
\hline $\mathrm{C} 16$ & Wood and Cork & H51 & Air transport \\
\hline $\mathrm{C} 17$ & Paper Products & H52 & Warehousing \\
\hline $\mathrm{C} 18$ & Printing and Media & H53 & Postal \\
\hline C19 & Petroleum Products & I & Accommodation \& Food serv. \\
\hline $\mathrm{C} 20$ & Chemicals & $\mathrm{J} 58$ & Publishing Act. \\
\hline $\mathrm{C} 21$ & Pharmaceutical & J59_J60 & Media Production \\
\hline $\mathrm{C} 22$ & Rubber and Plastic & $\mathrm{J} 61$ & Telecom \\
\hline $\mathrm{C} 23$ & Other Non-metallic mineral & J62_J63 & Computer Programming, consultancy \\
\hline $\mathrm{C} 24$ & Basic Metals & K64 & Financial Services \\
\hline $\mathrm{C} 25$ & Metal products & K65 & Insurance \\
\hline $\mathrm{C} 26$ & Electronics and Computers & K66 & Auxiliary Financial Serv. \\
\hline $\mathrm{C} 27$ & Electrical Equipment & L68 & Real Estate \\
\hline $\mathrm{C} 28$ & Machinery \& Equipment & M69_M70 & Legal and Accounting \\
\hline $\mathrm{C} 29$ & Motor vehicles & M71 & Architectural and engineering act. \\
\hline $\mathrm{C} 30$ & Transport equipment & M72 & Scientific Research \\
\hline C31_C32 & Furniture \& other manufac. & M73 & Advertising and market research \\
\hline C33 & Installation of machinery & M74_M75 & Other professional activities \\
\hline D35 & Electricity \& Gas & $\mathrm{N}$ & Administrative and support act. \\
\hline E36 & Water Collection Activities & O84 & Public admin and defence \\
\hline E37-E39 & Waste Collection Activities & P85 & Education \\
\hline & & $\mathrm{Q}$ & Health \\
\hline & & R_S & Other services \\
\hline
\end{tabular}


Copyright @ 2018 @ the author(s). Discussion papers are in draft form. This discussion paper is distributed for purposes of comment and discussion only. It may not be reproduced without permission of the copyright holder. Copies of working papers are available from the author. 